\title{
Meta-analysis of the effect of structured exercise training on cardiorespiratory fitness in Type 2 diabetes mellitus
}

\author{
N. G. Boulé 1 , G. P. Kenny ${ }^{1}$, E. Haddad ${ }^{2}$, G. A. Wells ${ }^{3,4}$, R. J. Sigal ${ }^{1,3}$ \\ ${ }^{1}$ School of Human Kinetics, University of Ottawa, Ottawa, Ontario, Canada \\ ${ }^{2}$ Faculty of Medicine, University of Ottawa, Ottawa, Ontario, Canada \\ ${ }^{3}$ Department of Medicine, University of Ottawa, Ottawa, Ontario, Canada \\ ${ }^{4}$ Department of Epidemiology and Community Medicine, University of Ottawa, Ottawa, Ontario, Canada
}

\section{Abstract}

Aims/hypothesis. Low cardiorespiratory fitness is a powerful and independent predictor of mortality in people with diabetes. Several studies have examined the effects of exercise on cardiorespiratory fitness in Type 2 diabetic individuals. However, these studies had relatively small sample sizes and highly variable results. Therefore the aim of this study was to systematically review and quantify the effects of exercise on cardiorespiratory fitness in Type 2 diabetic individuals.

Methods. MEDLINE, EMBASE, and four other databases were searched up to March 2002 for randomized, controlled trials evaluating effects of structured aerobic exercise interventions of 8 weeks or more on cardiorespiratory fitness in adults with Type 2 diabetes. Cardiorespiratory fitness was defined as maximal oxygen uptake $\left(\mathrm{VO}_{2 \max }\right)$ during a maximal exercise test.

Results. Seven studies, presenting data for nine randomized trials comparing exercise and control groups (overall $n=266$ ), met the inclusion criteria. Mean exercise characteristics were as follows: 3.4 sessions per week, 49 min per session for 20 weeks. Exercise intensity ranged from $50 \%$ to $75 \%$ of $\mathrm{VO}_{2 \max }$. There was an $11.8 \%$ increase in $\mathrm{VO}_{2 \max }$ in the exercise group and a $1.0 \%$ decrease in the control group (post intervention standardized mean difference $=0.53$, $p<0.003$ ). Studies with higher exercise intensities tended to produce larger improvements in $\mathrm{VO}_{2 \max }$. Exercise intensity predicted post-intervention weighted mean difference in $\mathrm{HbA}_{1 \mathrm{c}}(\mathrm{r}=-0.91, p=0.002)$ to a larger extent than did exercise volume $(\mathrm{r}=-0.46$, $p=0.26$ ).

Conclusions/interpretation. Regular exercise has a statistically and clinically significant effect on $\mathrm{VO}_{2 \max }$ in Type 2 diabetic individuals. Higher intensity exercise could have additional benefits on cardiorespiratory fitness and $\mathrm{HbA}_{1 \mathrm{c}}$. [Diabetologia (2003) 46: 1071-1081]

Keywords Meta-analysis, Type 2 diabetes mellitus, exercise, fitness, oxygen consumption.
The maximal amount of oxygen consumed during exercise $\left(\mathrm{VO}_{2 \max }\right)$ has been used for decades by exercise physiologists to determine the maximum exercise ca-

Received: 15 January 2003 / Revised: 2 April 2003

Published online: 10 July 2003

(C) Springer-Verlag 2003

Corresponding author: Dr. R. J. Sigal, Clinical Epidemiology Program, Ottawa Health Research Institute, 1053 Carling Avenue, Room C-408, Ottawa, Ontario, Canada K1Y 4E9

E-mail: rsigal@ohri.ca

Abbreviations: $\mathrm{VO}_{2 \max }$, maximal oxygen consumption. pacities of athletes. In recent decades, $\mathrm{VO}_{2 \max }$ has had a growing importance in clinical settings and has become the gold standard measure of cardiovascular fitness and exercise capacity [1]. There is evidence from large cohort studies that low cardiorespiratory fitness is a powerful and independent predictor of long-term cardiac mortality in people with diabetes [2, 3, 4], even after controlling for traditional risk factors such as age, hypercholesterolaemia, smoking, and hypertension and excluding individuals with evidence of coronary ischaemia during testing. Furthermore, in non-diabetic subjects undergoing repeated maximal 
exercise tests years apart, improvement over time in cardiorespiratory fitness was associated with lower subsequent mortality rates, and deterioration in cardiorespiratory fitness over time was associated with higher subsequent mortality rates $[5,6]$.

The determination of $\mathrm{VO}_{2 \max }$ in people with Type 2 diabetes could be of particular interest since it has been suggested that people with Type 2 diabetes, even in the absence of known complications, have a reduced $\mathrm{VO}_{2 \max }$ compared to age, body mass and activity matched controls $[7,8]$. Furthermore, many characteristics of skeletal muscle are associated with both low insulin sensitivity and low cardiorespiratory fitness (i.e. decreased capillary density, decreased proportion of Type 1 muscle fibres, higher glycolytic to oxidative enzyme ratio) $[8,9,10,11,12,13,14,15]$.

In addition to having beneficial effects on hyperglycaemia, hypertension and dislipedaemia, physical activity is essential for the management of Type 2 diabetes because it is the only intervention that directly affects cardiorespiratory fitness. Cardiorespiratory fitness is determined both by habitual exercise levels and by genetic factors, and individual improvements in cardiorespiratory fitness can vary greatly in response to identical structured aerobic exercise programs [16]. There is no reason to suspect that the condition of diabetes itself (in the absence of neuropathy, cardiovascular disease and orthopaedic limitations) affects the capacity of $\mathrm{VO}_{2 \max }$ to change in response to exercise training. However, the $\mathrm{VO}_{2 \max }$ response to exercise training in people with Type 2 diabetes could be different from what is expected in the non-diabetic population since people with Type 2 diabetes have lower initial physical activity levels [17], lower initial $\mathrm{VO}_{2 \max }$ $[7,8]$ and perhaps a common genetic predisposition to both Type 2 diabetes and low physical fitness.

Given the association between improvement in cardiorespiratory fitness and reduced subsequent mortality in people without diabetes, even after adjustment or stratification for other known risk factors for mortality, it is clinically important to determine the extent to which cardiorespiratory fitness can be improved in people with diabetes using structured exercise programs. Unfortunately previous randomized control trials that have measured the effects of structured exercise training on $\mathrm{VO}_{2 \max }$ in adults with Type 2 diabetes have had small sample sizes and have led to variable results $[18,19,20,21,22,23,24]$. Therefore, the main objective of this study is to use the meta-analysis procedure to systematically review the effects of exercise training on $\mathrm{VO}_{2 \max }$. A meta-analysis is a rigorous process involving the systematic identification, appraisal, synthesis, and statistical aggregation of all relevant studies on a specific topic according to a predetermined and explicit method [25].

We recently published a meta-analysis showing that structured exercise interventions improve glycaemic control as reflected in $\mathrm{HbA}_{1 \mathrm{c}}$, while having little effect on body weight [26]. As higher $\mathrm{HbA}_{1 \mathrm{c}}$ is a key predictor of risk for both microvascular and macrovascular complications of diabetes, and structured exercise programs reduce $\mathrm{HbA}_{1 \mathrm{c}}$, we also wished to examine the relative importance of exercise intensity and exercise volume in determining changes in $\mathrm{HbA}_{1 \mathrm{c}}$ through exercise programs.

\section{Subjects and Methods}

Criteria for considering studies for the meta-analysis. The search strategy was developed to identify all relevant randomized clinical trials that included a structured aerobic exercise intervention in adults with Type 2 diabetes and a concurrent non-exercising Type 2 diabetic control group. Studies including a large resistance exercise component were excluded. If studies reported data for which it was impossible to discriminate between individuals with Type 2 diabetes and those with impaired glucose tolerance, we attempted to contact authors for the individual patient data.

All studies included in the meta-analysis were required to be at least 8 weeks in duration and include $\mathrm{VO}_{2 \max }$ measurements at baseline and at the end of the intervention period. To be considered valid, the maximal oxygen consumption values were required to be obtained during a maximal exercise test with either direct measures of oxygen consumption or a validated estimation of oxygen consumption. By definition, $\mathrm{VO}_{2 \max }$ could not be exceeded, even with an increase in exercise intensity. However, in a clinical setting with older sedentary patients, a plateau in oxygen consumption is rarely achieved because of factors such as leg fatigue and discomfort. Therefore, it is customary to refer to $\mathrm{VO}_{2 \max }$ as the peak oxygen consumption during incremental exercise [1].

An exercise intervention was defined as a predetermined supervised program consisting of continuous aerobic physical activity, described within the corresponding manuscript. We confined our analysis to structured, supervised interventions rather than studies in which people were simply encouraged to exercise on their own, because in unsupervised exercise it would be problematic to estimate exercise intensity and volume. In order to be included, studies in which qualified personnel did not directly supervise exercise sessions were required to assess compliance using exercise diaries. Studies that included drug co-intervention were excluded from the analysis.

Search strategy for identification of studies. We carried out computer-based searches up to and including March 2002 (MEDLINE, EMBASE, Sport Discuss, Health Star, Dissertation Abstracts and the Cochrane Controlled Trials Register). The reference lists of major textbooks, review articles and of all included articles identified by the search were hand searched to find other potentially eligible studies. Potential missing articles and unpublished literature were sought from contact with experts in the field. Studies were not excluded due to their language of publication.

The computer-based search strategy included common text words and Medical Subject Headings (MeSH) terms related to exercise and Type 2 diabetes. The MEDLINE and EMBASE searches were limited to human subjects and utilized a validated and highly sensitive search filter for randomized controlled trials [27].

Data extraction. Data were extracted in duplicate and entered in Review Manager (RevMan 4.1, Cochrane Collaboration, 
Oxford, UK), statistical software from the Cochrane Collaboration which permits double data entry for accuracy. The primary authors of potentially eligible studies were contacted when necessary to resolve ambiguities in their reported methodologies or results, and to seek additional pertinent information that could have been gathered but not described in the published manuscript. In one case, the post-intervention standard deviations (SD) were not available [18]. In this case we imputed the baseline standard deviation. This was assumed to be valid since baseline and post-intervention standard deviation were found to be similar within other trials. In one study [20], means and measures of dispersion were approximated from figures in the manuscripts using an image scanner (Compaq RT615CTW, resolution 200 dpi, Compaq Computer Corp, Houston, Tex., USA), as described previously [28].

The characteristics of the exercise interventions were extracted, including the type, frequency, duration, intensity and energy cost. The Compendium of Physical Activities was used to estimate the exercise intensity in terms of metabolic equivalents (METs) [29]. One MET corresponds to an oxygen consumption of $3.5 \mathrm{ml} \mathrm{O} \cdot \mathrm{kg}^{-1} \cdot \mathrm{min}^{-1}$. Exercise volume, or total energy expenditure on exercise (total MET.hrs) was calculated by multiplying the intensity in METs by total time spent exercising (number of exercise sessions multiplied by duration of each exercise session). The relative exercise intensity (percentage of $\mathrm{VO}_{2 \max }$ ) was extracted directly from studies or estimated from the exercise heart rates according to previously established guidelines [30]. The methodological quality of each included trial was assessed using a validated five-point scale [31]. This instrument assigned scores for reported randomization, blinding and withdrawals. In addition to this quality scoring, we recorded separately whether allocation concealment was adequate [32].

Statistical analysis. Statistical analysis was done using Review Manager Software (RevMan 4.1, Cochrane Collaboration, Oxford, UK) and JMP Software 3.1.6.2 (SAS Institute, Cary, N.C., USA). In each study the size of the effect of the intervention was calculated by the difference between the means of the exercise and control groups at the end of the intervention period. Each mean difference was weighted according to the inverse variance method [33]. Since $\mathrm{VO}_{2 \max }$ was reported in different units $\left(\mathrm{ml} \cdot \mathrm{kg}^{-1} \cdot \mathrm{min}^{-1}\right.$ or $\left.\mathrm{L} \cdot \mathrm{min}^{-1}\right)$ the mean differences were standardized by dividing them by the within-group standard deviation. The standardization of these units was assumed to be valid since there were no changes in body weight during the trials [26]. The overall result is known as the standardized mean difference. The standardized mean differences in each study were pooled with a random effects model [34]. The Chi-square test for heterogeneity was done, and when statistically significant heterogeneity was found, subgroup analyses were carried out to attempt to explain the heterogeneity between the studies.

We did a meta-regression analysis to explore which characteristics of the exercise programs best predicted the post-intervention standardized mean difference in $\mathrm{VO}_{2 \max }$ or the post-intervention mean difference in $\mathrm{HbA}_{1 \mathrm{c}}$. In all meta-regression analysis models, each study was assigned a weight according the inverse of the variance of the dependant variable [33]. Exercise characteristics such as exercise frequency (sessions/week), absolute intensity (METs), relative intensity $\left(\% \mathrm{VO}_{2 \max }\right)$, duration (weeks), length ( $\mathrm{min} /$ session), weekly exercise volume (MET'h per week) and total exercise volume $(\mathrm{MET} \cdot \mathrm{h})$ were entered as independent variables in regressions models with the post-intervention standardized mean difference in $\mathrm{VO}_{2 \max }$ or the post-intervention mean difference in $\mathrm{HbA}_{1 \mathrm{c}}$ as the dependent variable. A $p$ value of less than 0.05 was considered statistically significant.

\section{Results}

Description of included trials. The computer search initially yielded over 3000 potential articles. The literature search was not designed to initially limit the search results to studies with $\mathrm{VO}_{2 \max }$ data, and the large majority of these articles were subsequently found to be ineligible because of the absence of $\mathrm{VO}_{2 \max }$ measures. The other principal reasons for the exclusion of trials were: (i) the absence of a randomized control group, (ii) the short duration of the study ( $<8$ weeks), (iii) subjects without Type 2 diabetes, (iv) non-human subjects, (v) unstructured/unsupervised lifestyle intervention.

Of the studies otherwise meeting the inclusion criteria, two trials (three articles) were not included since the fitness test was not a maximal aerobic test $[35,36$, 37], three trials (four articles) were excluded because they included a large resistance training component combined with non-continuous aerobic exercise [38, $39,40,41]$ and two articles were excluded since we were unable to differentiate between subjects with and without diabetes $[42,43]$. Four of the potential articles did not have baseline and post-training $\mathrm{VO}_{2 \max }$ data available [44, 45, 46, 47] while one trial (two articles) measured post training $\mathrm{VO}_{2 \max } 6$ months after the initiation of the 10-week exercise intervention [48, 49] and was therefore excluded. Articles were also excluded for the following reasons: one because the exercise intervention alternated between 3 months of exercise and 3 months without exercise [50], one because the intervention did not result in an increase in physical activity [51] and one because the control group was substantially different from the exercise group (the control group was composed of less healthy people who could not exercise due to musculoskeletal problems, asthma or hypertension) [52].

Eventually there were 15 eligible articles, but there were several multiple publications from the same trials $[53,54,55,56,57,58,59,60]$. Therefore, there were actually seven trials with appropriate $\mathrm{VO}_{2 \max }$ data that were included in the analysis. Two of these trials presented data for two comparisons (Table 1), therefore nine comparisons were included. One of these trials [18] had a $2 \times 2$ factorial design in which participants were assigned to four groups (Exercise, Diet, Exercise + Diet and Control). For this trial we were able to analyze two comparisons: (i) exercise and diet compared with diet alone, (ii) exercise alone compared with control. The second trial that had more than one comparison analyzed the data separately for men and women [21], we will refer to these comparisons as Vanninen (men) and Vanninen (women).

A total of 266 participants were included in the seven trials that measured maximal oxygen consumption. The mean age of participants in studies for which this information was available was 55.7 years, the mean duration of diabetes was 4.1 years, and $40 \%$ of partici- 


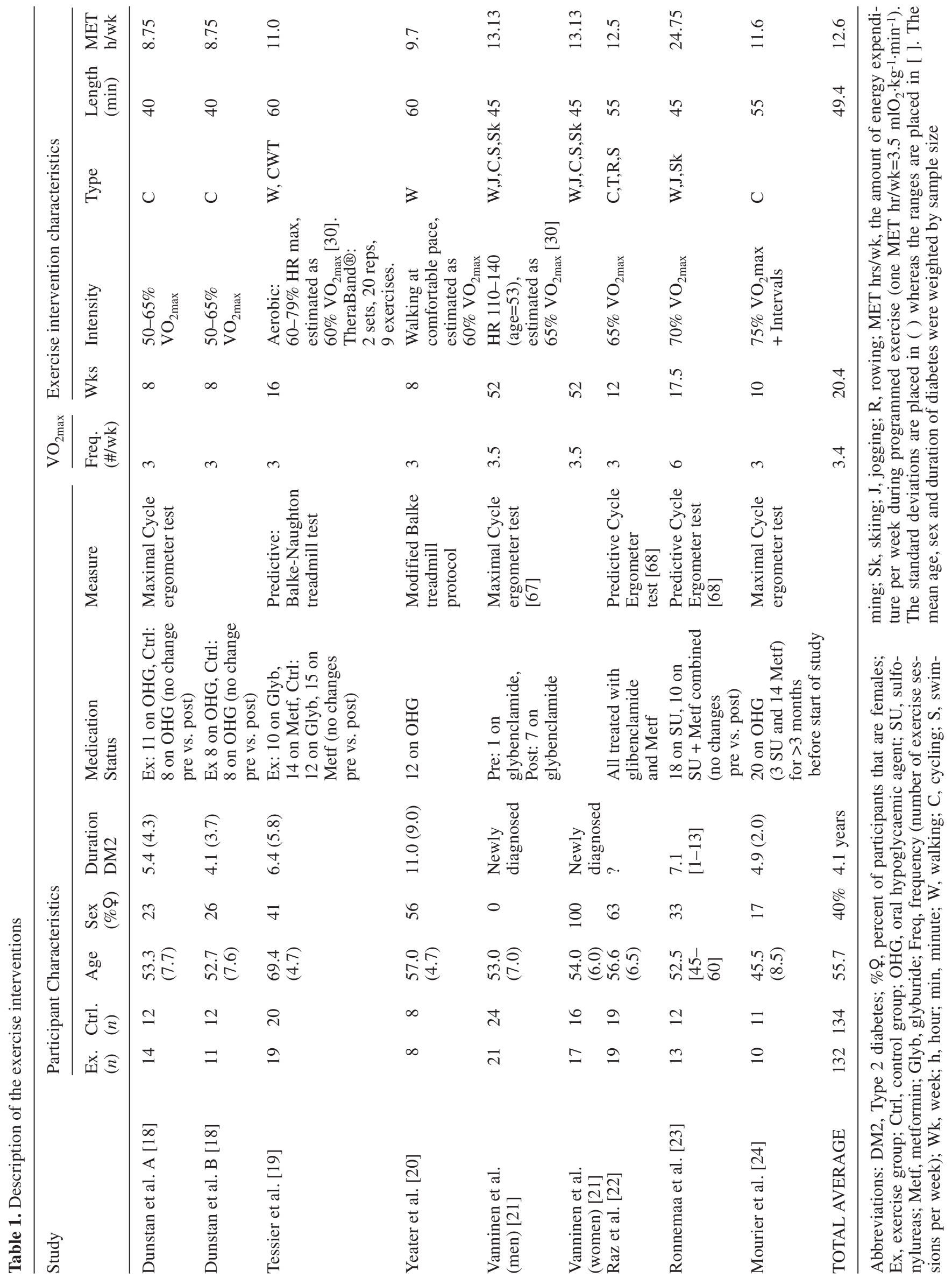




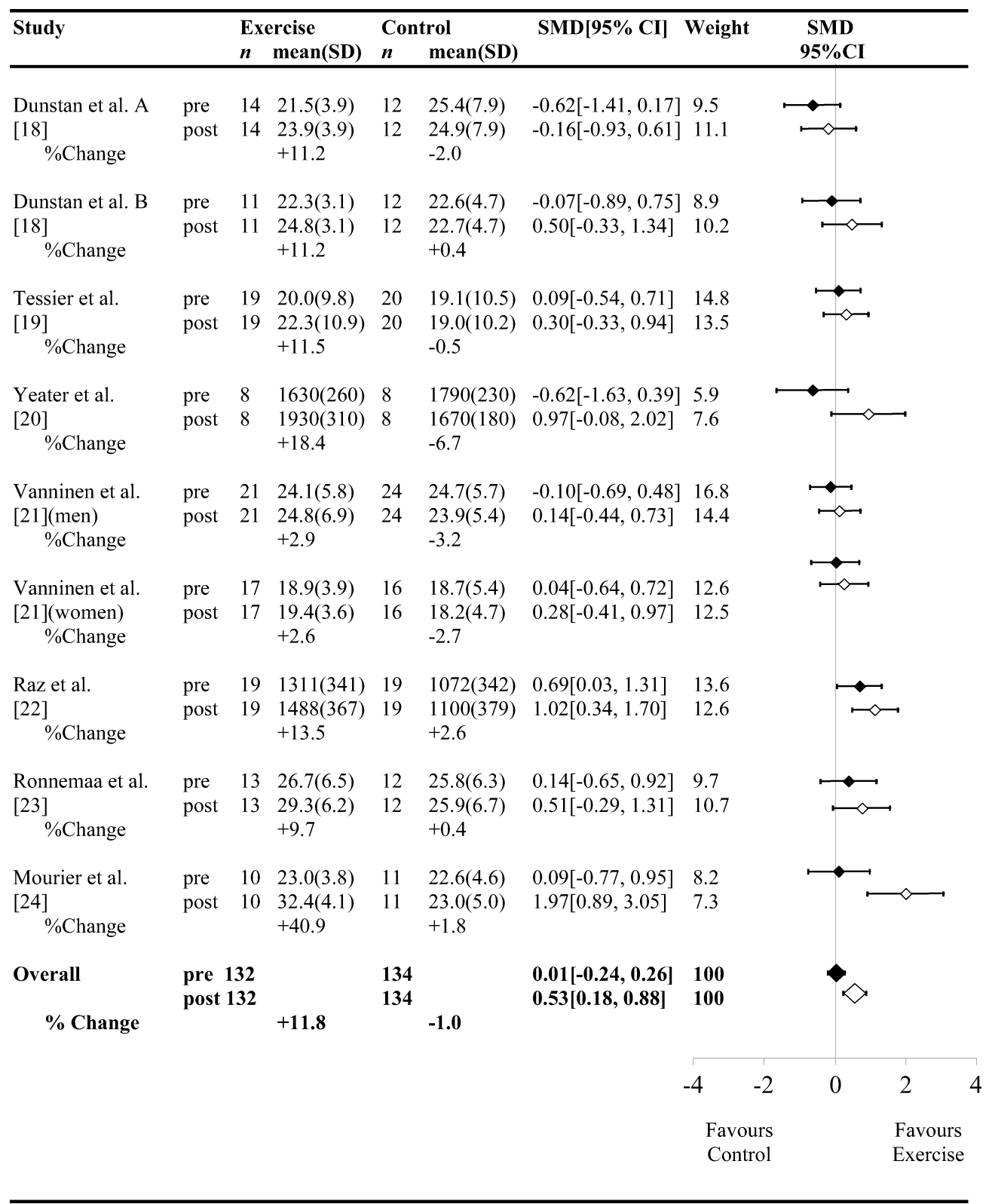

Fig. 1. Differences in $\mathrm{VO}_{2 \max }$ at baseline and post-intervention for exercise versus non-exercise control groups. Baseline (pre): Test for heterogeneity, Chi-square $=8.36, p=0.4$. Test for overall effect, $\mathrm{z}=0.10, p=0.9$. Post-intervention (post): Test for heterogeneity, Chi-square $=15.04, p=0.06$. Test for overall effect, $\mathrm{z}=2.98, p=0.003$. $n=$ number of participants, $\mathrm{SD}=$ standard deviation $\mathrm{CI}=$ confidence interval, $\mathrm{SMD}=$ standardised mean difference. Studies are placed in ascending order of the intensity of the exercise intervention and pooled with a random effects model. $\mathrm{VO}_{2 \max }$ units are in $\mathrm{ml} \cdot \mathrm{kg}^{-1} \cdot \mathrm{min}^{-1}$ or in $\mathrm{ml} \cdot \mathrm{min}^{-1}$. Black diamonds represent the standardized mean difference for pre-intervention $\mathrm{VO}_{2 \max }$. White diamonds represent the standardized mean difference in post-intervention $\mathrm{VO}_{2 \max }$

pants were female (Table 1). The quality of the trials according to a previously validated scale [31] was moderate to low. The mean score was $1.9 \pm 0.4$ out of a possible five points. All of the trials were randomized controlled trials, none of the trials was double blinded or had adequate allocation concealment. Five trials had adequately described dropouts [18, 19, 22, 23, 24], there were no dropouts in one of the studies [20], and one of the studies did not comment on dropouts [21].

The compliance to the exercise interventions was relatively high. In four studies $[18,19,22,24]$ the mean participation rate was above $90 \%$, one article [23] simply indicated that compliance was good and one study did not comment on compliance [20]. In one study [21], compliance was relatively low. The proportion of participants participating in regular recreational exercise was increased to a higher level in the intervention group (41\%) compared to the control group (19\%) but the difference was not statistically significant [21].

The exercise interventions in each study are described in Table 1. The exercise interventions included 
A.

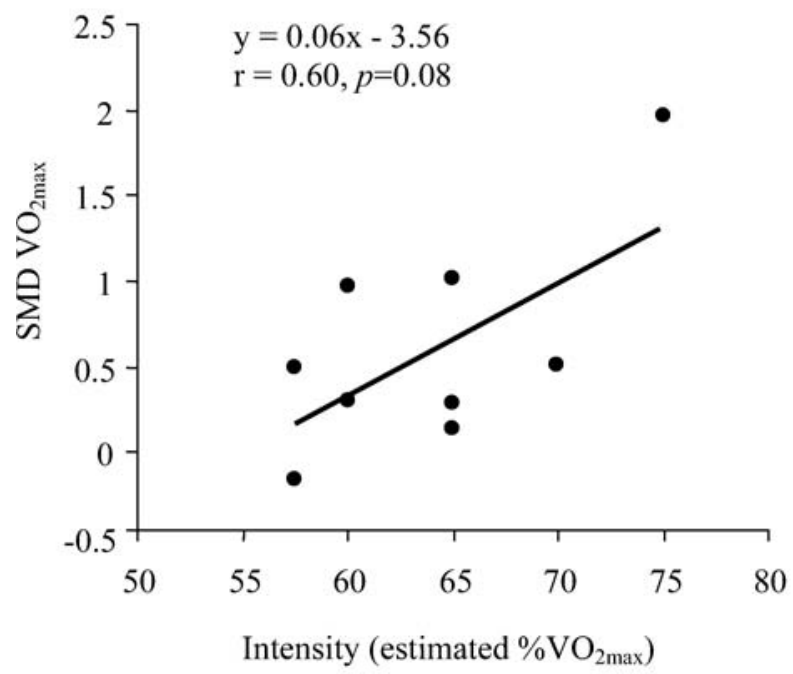

B.

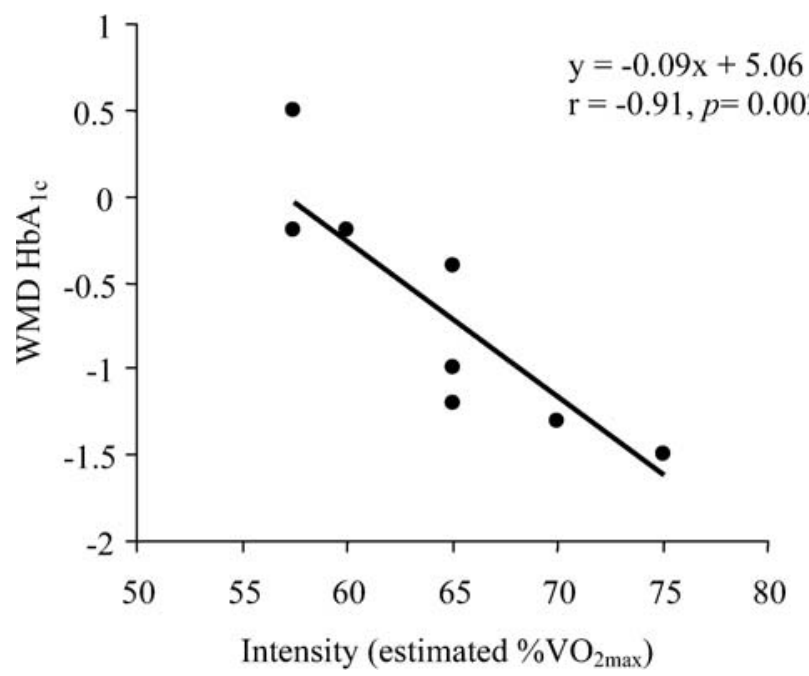

Fig. 2. Associations between exercise intensity (estimated $\% \mathrm{VO}_{2 \max }$ ) or exercise volume (MET $\left.\mathrm{h} / \mathrm{wk}\right)$ and the post-intervention standardized mean difference (SMD) in $\mathrm{VO}_{2 \max }$ between the exercise and control group or the post-intervention weighted mean difference (WMD) in $\mathrm{HbA}_{1 \mathrm{c}}$ between the exercise and control groups. Correlations were weighted by the inverse of the variance of the dependant variable

a mean of 3.4 workouts per week, each $49 \mathrm{~min}$ on average (including approximately 10-15 minutes of warm-up and cool-down), for a mean of 20 weeks. The intensity of aerobic exercise was moderate in most studies and typically consisted of walking or cycling. One study added light resistance training with elastic bands (TheraBand) to their aerobic training program [19]. As expected, most studies did not de-
C.

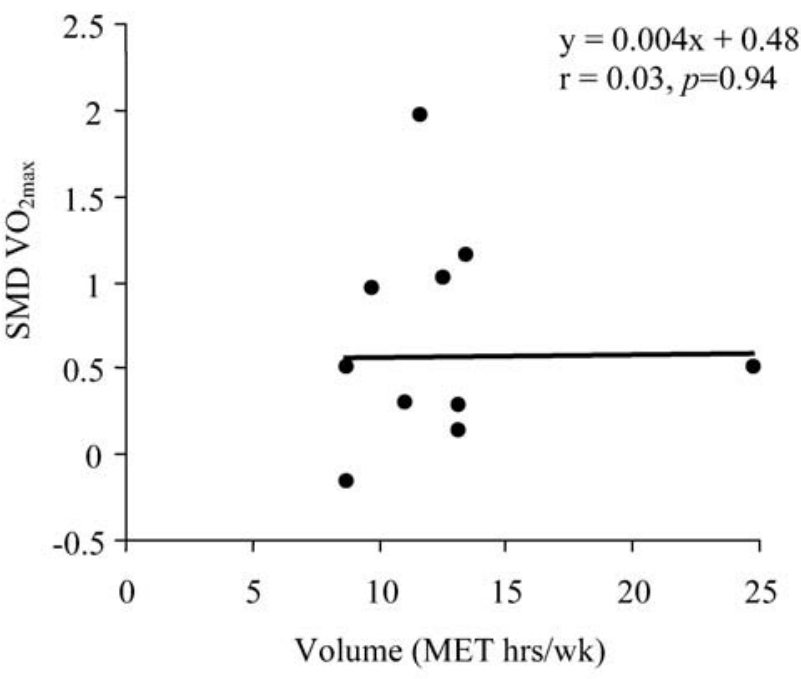

D.

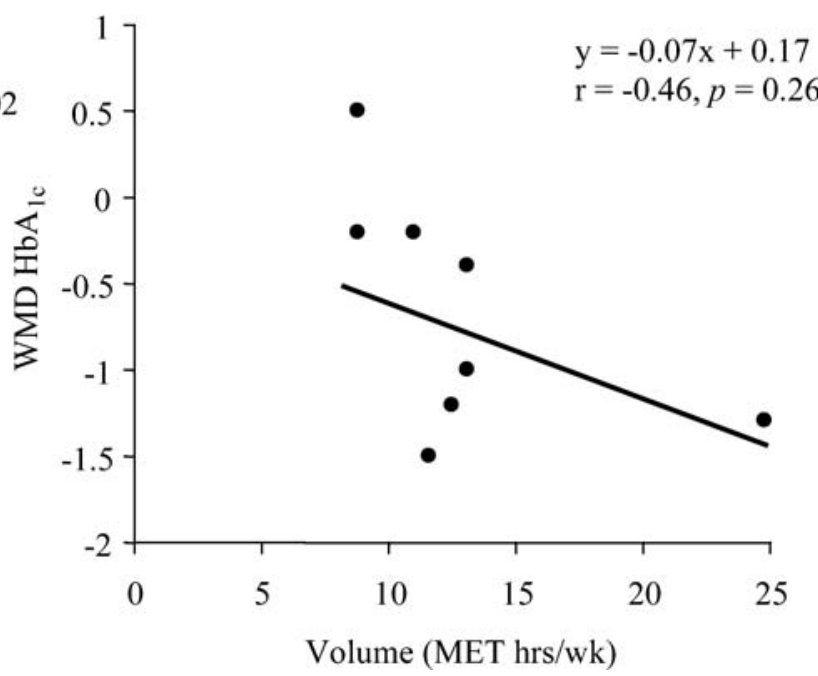

scribe having specific criteria, such as the ACSM criteria [61], to establish a true $\mathrm{VO}_{2 \max }$. The only study that did describe criteria for reaching a true $\mathrm{VO}_{2 \max }$ value indicated that $\mathrm{VO}_{2}$ did not reach a plateau in most participants [24]. Therefore, the $\mathrm{VO}_{2 \max }$ values reported most likely represent $\mathrm{VO}_{2 \text { peak }}$ rather than true $\mathrm{VO}_{2 \max }$.

Effects of exercise on VO2max. For the 212 participants in whom data were presented as $\mathrm{ml} \cdot \mathrm{kg}^{-1} \cdot \mathrm{min}^{-1}$ the mean baseline $\mathrm{VO}_{2 \max }$ was $22.4 \mathrm{ml} \cdot \mathrm{kg}^{-1} \cdot \mathrm{min}^{-1}$. Since some studies reported $\mathrm{VO}_{2 \max }$ values in $\mathrm{ml} \cdot \mathrm{kg}^{-1} \cdot \mathrm{min}^{-1}$ and others reported in $\mathrm{L} \cdot \mathrm{min}^{-1}$, it was necessary to pool the data using standardized mean difference rather than weighted mean difference. Standardized mean $\mathrm{VO}_{2 \max }$ at baseline was equal between control and intervention groups. Mean post-interven- 
tion $\mathrm{VO}_{2 \max }$ was higher in exercise groups compared to control groups (standardized mean difference $=0.53 \mathrm{SD}, p=0.003$ ) (Fig. 1). When considering the weight assigned to each study, this corresponds to an $11.8 \%$ increase in $\mathrm{VO}_{2 \max }$ in the exercise group and a $1.0 \%$ decrease in the control group. The calculation was done with a random effects model since the Chisquare test suggested a tendency towards heterogeneity (i.e. that the effect of exercise on $\mathrm{VO}_{2 \max }$ across studies was not homogeneous). This heterogeneity was mostly explained by the larger increase in $\mathrm{VO}_{2 \max }$ in one study [24]. In this study, the participants who were assigned to the exercise were training at relatively high intensities compared to the other studies (Table 1) and $\mathrm{VO}_{2 \max }$ increased by $40.9 \%$ in the exercise group and did not change in the control group (post intervention standardized mean difference $=1.97 \mathrm{SD}$, $p=0.0004)$. In contrast, in the eight comparisons with exercise intensities less than or equal to $70 \%$ of $\mathrm{VO}_{2 \max }$ there was a much smaller $9.5 \%$ (range: $2.6 \%-18.4 \%$ ) increase in $\mathrm{VO}_{2 \max }$ in the exercise group (post intervention standardized mean difference $=0.40 \mathrm{SD}, p=0.003)$. A sensitivity analysis revealed no differences between the trials that measured $\mathrm{VO}_{2 \max }$ directly $[18,20,21,24]$ and those that calculated $\mathrm{VO}_{2 \max }$ according to validated equations [19, 22, 23].

Meta-regression analyses. The association between estimated exercise intensity $\left(\% \mathrm{VO}_{2 \max }\right)$ and the standardized mean difference in $\mathrm{VO}_{2 \max }$ was of borderline significance ( $\mathrm{r}=0.60, p=0.08$, Fig. $2 \mathrm{~A})$. None of the other exercise characteristics, such as the exercise frequency in sessions per week $(\mathrm{r}=-0.10, p=0.79)$, the duration of the training program in weeks $(\mathrm{r}=-0.38, p=0.32)$, the length of each session in $\min (\mathrm{r}=0.28, p=0.15)$, the exercise volume in MET'h per week $(\mathrm{r}=0.03, p=0.94)$ or the exercise volume in total MET $\cdot \mathrm{h}(\mathrm{r}=-0.35, p=0.35)$ predicted the standardized mean difference in $\mathrm{VO}_{2 \max }$. When both exercise volume (MET/h/week) and exercise intensity $\left(\% \mathrm{VO}_{2 \max }\right)$ were entered, only exercise intensity predicted the standardized mean difference in $\mathrm{VO}_{2 \max }$ (partial $\mathrm{r}=0.75, p=0.03$ ).

The second question to address is the extent to which exercise intensity per se or the standardized mean difference in $\mathrm{VO}_{2 \max }$ is associated with the mean difference in $\mathrm{HbA}_{1 \mathrm{c}}$. Eight of the nine comparisons (250 of 266 participants), had $\mathrm{HbA}_{1 \mathrm{c}}$ data [18, 19, 21, 22, 23, 24]. Baseline $\mathrm{HbA}_{1 \mathrm{c}}$ values did not differ between exercise and control subjects. The post-intervention $\mathrm{HbA}_{1 \mathrm{c}}$ values were lower in the exercise groups [weighted mean difference $=-0.71,95 \%$ confidence interval $(-1.10,-0.32), p=0.0004]$. For a complete description of changes in $\mathrm{HbA}_{1 \mathrm{c}}$ refer to our previous meta-analysis [26]. The relative exercise intensity $\left(\% \mathrm{VO}_{2 \max }\right)$ was the variable that showed the strongest association with the mean difference in $\mathrm{HbA}_{1 \mathrm{c}}$ between the exercise and the control groups $(\mathrm{r}=-0.91, p=0.002$, Fig. 2B). However, the absolute exercise intensity (METs) was not associated with the weighted mean difference in $\mathrm{HbA}_{1 \mathrm{c}} \quad(\mathrm{r}=-0.33$, $p=0.42$ ). The relationship between exercise volume expressed as total MET'h or MET/h/week and mean differences in $\mathrm{HbA}_{1 \mathrm{c}}$ between the exercise and control group was not significant $(\mathrm{r}=-0.12, p=0.8$ and $\mathrm{r}=$ $-0.46, p=0.26$, respectively). These correlations increased after eliminating the study in which adherence rates were low [21], but were still not statistically significant. When both exercise volume (MET.h/week) and exercise intensity $\left(\% \mathrm{VO}_{2 \max }\right)$ were entered, only exercise intensity predicted the weighted mean difference in $\mathrm{HbA}_{1 \mathrm{c}}$ (partial $\mathrm{r}=0.89, p=0.007$ ).

The relationship between the post-intervention standardized mean difference in $\mathrm{VO}_{2 \max }$ and the postintervention weighted mean difference in $\mathrm{HbA}_{1 \mathrm{c}}$ was statistically significant $(\mathrm{r}=-0.72, p=0.04)$.

\section{Discussion}

As low cardiorespiratory fitness is a modifiable risk factor associated with increased mortality in people without diabetes, it is clinically important to determine the extent to which the low fitness often observed in people with diabetes is also modifiable. The present meta-analysis determined that aerobic fitness can be improved in people with Type 2 diabetes. Overall, there was an $11.8 \%$ increase in $\mathrm{VO}_{2 \max }$ in the exercise group and a $1.0 \%$ decrease in $\mathrm{VO}_{2 \max }$ in the control group. In meta-regression analysis, differences in $\mathrm{VO}_{2 \max }$ across studies tended to be associated with the intensity of the exercise. In the study where the exercise intensity was $75 \%$ of $\mathrm{VO}_{2 \max }$ [24], $\mathrm{VO}_{2 \max }$ increased by $40.9 \%$ whereas the weighted average increase was only $9.5 \%$ for the studies in which exercise intensity was lower. It is also interesting to note that the study with the highest exercise intensity was also the study with the youngest participants (from 45.5 \pm 8.5 years of age). More intense exercise also produced greater improvements in blood glucose control, reflected in reductions in $\mathrm{HbA}_{1 \mathrm{c}}$, and the study using the most intense exercise was also the one in which the greatest reduction of $\mathrm{HbA}_{1 \mathrm{c}}$ was observed (post intervention $\mathrm{HbA}_{1 \mathrm{c}}$ was $1.5 \%$ lower in the exercise group compared to the control group) [24]. Estimated total weekly energy expenditure on exercise (exercise volume) was not an important predictor of either the $\mathrm{VO}_{2 \max }$ or the $\mathrm{HbA}_{1 \mathrm{c}}$ response to exercise. When both exercise volume and exercise intensity were entered, only exercise intensity predicted either the $\mathrm{HbA}_{1 \mathrm{c}}$ or the $\mathrm{VO}_{2 \max }$ response.

Exercise could have many potential benefits other than improving cardiorespiratory fitness, including improvements in glucose disposal, insulin signalling, and lipid profile, reduction of vascular inflammation as reflected by reduced C-reactive protein, improved 
endothelial function and facilitation of weight maintenance. Nevertheless, cardiorespiratory fitness is an important independent modifiable risk factor in its own right. Even the modest $\mathrm{VO}_{2 \max }$ increase of $9.5 \%$ (corresponding to approximately $2.1 \mathrm{ml} \cdot \mathrm{kg}^{-1} \cdot \mathrm{min}^{-1}$ ) observed in the six studies with exercise intensity less than or equal to $70 \%$ of $\mathrm{VO}_{2 \max }$ is likely to have beneficial consequences on morbidity and mortality. In a large cohort study [5], it was found that for every increase in Balke protocol treadmill time of $1 \mathrm{~min}$, equivalent to an increase of $1.44 \mathrm{ml} \cdot \mathrm{kg}^{-1} \cdot \mathrm{min}^{-1}$ $\mathrm{VO}_{2 \max }$, between two examinations there was a $7.9 \%$ reduction in overall mortality. Extrapolating from these results, the seemingly modest $2.1 \mathrm{ml} \cdot \mathrm{kg}^{-1} \cdot \mathrm{min}^{-1}$ $\mathrm{VO}_{2 \max }$ increase in the moderate-intensity exercise studies would be predicted to result in a $12 \%$ reduction in overall mortality. In order to obtain larger improvements in cardiorespiratory fitness, higher intensity exercise training might be necessary. It is also important to note that the increases in $\mathrm{VO}_{2 \max }$ induced by exercise training will only be sustained if the exercise stimulus is maintained. Therefore, active lifestyle changes must be sustained beyond these relatively short-term exercise interventions if the risk reduction is to be preserved.

Although previous small studies have suggested that patients with Type 2 diabetes had lower cardiorespiratory fitness than control subjects of similar age and body mass [7, 8], the current meta-analysis pooling data from seven studies and 266 people with diabetes shows a surprisingly low initial $\mathrm{VO}_{2 \max }$ $\left(22.4 \mathrm{ml} \cdot \mathrm{kg}^{-1} \cdot \mathrm{min}^{-1}\right)$. To put this in perspective, a recent American Heart Association Scientific Statement indicates that a normal value for maximal oxygen uptake for a 50 -to 59 -year-old is $36 \pm 7.1 \mathrm{ml} \cdot \mathrm{kg}^{-1} \cdot \mathrm{min}^{-1}$ for men and $29 \pm 5.4 \mathrm{ml} \cdot \mathrm{kg}^{-1} \cdot \mathrm{min}^{-1}$ for women [1]. In practical terms, an activity having an intensity above $60 \%$ of $\mathrm{VO}_{2 \max }$ can start to be considered hard. Therefore, for a person with a $\mathrm{VO}_{2 \max }$ of $22.4 \mathrm{ml} \cdot \mathrm{kg}^{-1} \cdot \mathrm{min}^{-1}$ any activity above four METs (equivalent to $14 \mathrm{ml} / \mathrm{kg} / \mathrm{min}$ ) could feel hard to maintain. According to the updated compendium of physical activity most home activities are below four METs, however some activities, such as sweeping the garage, several lawn and garden activities, many home repair activities and walking up stairs could equal or exceed 4 METs [62]. The difficulty presented by a common activity such as climbing stairs could discourage people from this type of activity. Consequently, improving cardiorespiratory fitness could make many daily activities more enjoyable, improve quality of life and promote an active lifestyle.

The mean baseline $\mathrm{VO}_{2 \max }$ derived from our metaanalysis is not meant to be representative of all people with Type 2 diabetes. The values obtained were based on samples of people who are willing to volunteer for an exercise study and who were selected to have a minimum of cardiovascular or orthopaedic limitations.
It is therefore likely that the exercise capacity in a representative sample of people with Type 2 diabetes would be even lower than what was estimated from our study. It is possible that both low $\mathrm{VO}_{2 \max }$ and the occurrence of Type 2 diabetes are partly explained by a low level of habitual physical activity. Physical inactivity can lead to obesity, insulin resistance and Type 2 diabetes. Insulin resistance is associated with many abnormalities in muscle tissue such as an increase in muscle lipid content, impaired glycogen synthesis, an enzymatic disposition towards anaerobic generation of energy (high PFK/CS ratio), an increase in the proportion of Type 2 muscle fibres and a reduced capillary density $[9,10,11,63,64]$. These abnormalities could contribute to the lower $\mathrm{VO}_{2 \max }$ often seen in Type 2 diabetes. It has also been hypothesized that the lower $\mathrm{VO}_{2 \max }$ might be a consequence of a reduced rate of circulatory adjustments to an increased workload (i.e. cardiac output) $[8,65]$, or poor diffusion and utilization of oxygen at the level of skeletal muscle [12]. Despite this, our present analysis suggests that people with Type 2 diabetes respond to exercise training with similar increases in $\mathrm{VO}_{2 \max }$ as those reported in older healthy adults [66].

The quality scores of the included trials were relatively low (average score of 1.9 out of 5) on a previously validated scale for the assessment of the quality of randomized clinical trials [31]. This was primarily because none of the studies used double blinding (which may not be practical in exercise studies) or described a randomization process meeting current standards [31]. It is probably not realistic to have true double blinding in a trial with exercise as the intervention; this limitation is inherent to exercise studies. As two points in the Jadad scale reflect quality of double blinding, the maximum realistically achievable score on this scale for an exercise study would be three. Nevertheless, none of the included studies achieved a score of three, primarily because none of them described a randomization process meeting current standards. We are not aware of any studies that have shown an effect of placebo on either $\mathrm{VO}_{2 \max }$ or $\mathrm{HbA}_{1 \mathrm{c}}$, so the lack of double blinding probably is not a serious threat to internal validity of the exercise trials in this meta-analysis.

In our previous meta-analysis [26] we reported no relationship between exercise intensity (estimated METs using the compendium of physical activities) [29] and $\mathrm{HbA}_{1 \mathrm{c}}$. This earlier analysis included studies in which $\mathrm{VO}_{2 \max }$ was not measured (and thus intensity could not be assessed with precision) and resistance exercise studies (in which one would not expect a change in $\left.\mathrm{VO}_{2 \max }\right)$. In contrast, in the current metaanalysis exercise intensity was measured more precisely as a percentage of $\mathrm{VO}_{2 \max }$.

Our meta-regression analyses have limitations, chiefly due to the relatively small number of studies included, the lack of individual patient data, and the 
fact that only one study included an unequivocally vigorous exercise intervention at $75 \%$ of $\mathrm{VO}_{2 \max }$. This high intensity of exercise might prove difficult or even hazardous for many previously sedentary people with Type 2 diabetes, and we do not feel that this one study's very positive results would be sufficient to advocate high-intensity aerobic exercise for all people with diabetes. Nevertheless, we did observe a dose-response relationship between intensity of exercise and improvements in both $\mathrm{VO}_{2 \max }$ and $\mathrm{HbA}_{1 \mathrm{c}}$. These findings would provide support for encouraging Type 2 diabetic individuals who are already exercising at moderate intensity to consider increasing the intensity of their exercise because of possible additional benefits in both cardiorespiratory fitness and metabolic control. Future randomized clinical trials comparing more intense to less intense aerobic exercise in Type 2 diabetic subjects could help clarify the relationship between exercise intensity and changes in metabolic control.

In conclusion, the current meta-analysis suggests that in people with Type 2 diabetes, moderate intensity aerobic exercise training increases $\mathrm{VO}_{2 \max }$ by about $9.5 \%$ and intense aerobic exercise can increase it much more than this. Increases of this magnitude would be expected to reduce the risk of cardiovascular disease considerably. It is encouraging that, despite initially low $\mathrm{VO}_{2 \max }$, our findings using an evidence based approach suggest that people with Type 2 diabetes show statistically and clinically significant improvements in cardiorespiratory fitness in response to aerobic exercise interventions.

Acknowledgements. Mr. Boulé was supported by a Postgraduate Scholarship from the Natural Science and Engineering Research Council of Canada. Dr. Kenny was supported by a Career Scientist Award from the Ontario Ministry of Health and Long Term Care. Dr. Sigal was supported in part by a New Investigator Award from the Canadian Institutes of Health Research.

\section{References}

1. Fletcher GF, Balady GJ, Amsterdam EA et al. (2001) Exercise standards for testing and training: a statement for healthcare professionals from the American Heart Association. Circulation 104:1694-1740

2. Wei M, Gibbons LW, Kampert JB, Nichaman MZ, Blair SN (2000) Low cardiorespiratory fitness and physical inactivity as predictors of mortality in men with Type 2 diabetes. Ann Intern Med 132:605-611

3. Kohl HW, Gordon NF, Villegas JA, Blair SN (1992) Cardiorespiratory fitness, glycemic status, and mortality risk in men. Diabetes Care 15:184-192

4. Myers J, Prakash M, Froelicher V, Do D, Partington S, Atwood JE (2002) Exercise capacity and mortality among men referred for exercise testing. N Engl J Med 346:793801

5. Blair SN, Kohl HW, 3rd, Barlow CE, Paffenbarger RS Jr, Gibbons LW, Macera CA (1995) Changes in physical fit- ness and all-cause mortality. A prospective study of healthy and unhealthy men. JAMA 273:1093-1098

6. Erikssen G, Liestol K, Bjornholt J, Thaulow E, Sandvik L, Erikssen J (1998) Changes in physical fitness and changes in mortality. Lancet 352:759-762

7. Kunitomi M, Takahashi K, Wada J et al. (2000) Re-evaluation of exercise prescription for Japanese type 2 diabetic patients by ventilatory threshold. Diabetes Res Clin Pract 50:109-115

8. Regensteiner JG, Sippel J, McFarling ET, Wolfel EE, Hiatt WR (1995) Effects of non-insulin-dependent diabetes on oxygen consumption during treadmill exercise. Med Sci Sports Exerc 27:875-881

9. Lillioja S, Young AA, Culter CL et al. (1987) Skeletal muscle capillary density and fiber type are possible determinants of in vivo insulin resistance in man. J Clin Invest 80:415-424

10. Nyholm B, Qu Z, Kaal A et al. (1997) Evidence of an increased number of type IIb muscle fibers in insulin-resistant first-degree relatives of patients with NIDDM. Diabetes 46:1822-1828

11. Simoneau JA, Kelley DE (1997) Altered glycolytic and oxidative capacities of skeletal muscle contribute to insulin resistance in NIDDM. J Appl Physiol 83:166-171

12. Regensteiner JG, Bauer TA, Reusch JE et al. (1998) Abnormal oxygen uptake kinetic responses in women with type II diabetes mellitus. J Appl Physiol 85:310-317

13. Brandenburg SL, Reuch JEB, Bauer TA, Jeffers BW, Hiatt WR, Regensteiner JG (1999) Effects of exercise training on oxygen uptake kinetic responses in women with type 2 diabetes. Diabetes Care 22:1640-1646

14. Estacio RO, Regensteiner JG, Wolfel EE, Jeffers B, Dickenson M, Schrier RW (1998) The association between diabetic complications and exercise capacity in NIDDM patients. Diabetes Care 21:291-295

15. Albright A, Franz M, Hornsby G et al. (2000) American College of Sports Medicine position stand. Exercise and type 2 diabetes. Med Sci Sports Exerc 32:1345-1360

16. Bouchard C, An P, Rice T et al. (1999) Familial aggregation of $\mathrm{VO}(2 \mathrm{max})$ response to exercise training: results from the HERITAGE Family Study. J Appl Physiol 87: 1003-1008

17. Ford ES, Herman WH (1995) Leisure-time physical activity patterns in the U.S. diabetic population. Findings from the 1990 National Health Interview Survey-Health Promotion and Disease Prevention Supplement. Diabetes Care 18:27-33

18. Dunstan DW, Mori TA, Puddey IB et al. (1997) The independent and combined effects of aerobic exercise and dietary fish intake on serum lipids and glycemic control in NIDDM. A randomized controlled study. Diabetes Care 20:913-921

19. Tessier D, Ménard J, Fulop T et al. (2000) Effects of aerobic physical exercie in elderly with type 2 diabetes mellitus. Arch Gerontol Geriatr 31:121-132

20. Yeater RA, Ullrich IH, Maxwell LP, Goetsch VL (1990) Coronary risk factors in type II diabetes: response to lowintensity aerobic exercise. W V Med J 86:287-290

21. Vanninen E, Uusitupa M, Siitonen O, Laitinen J, Lansimies E (1992) Habitual physical activity, aerobic capacity and metabolic control in patients with newly-diagnosed Type 2 (non-insulin-dependent) diabetes mellitus: effect of 1-year diet and exercise intervention. Diabetologia 35:340-346

22. Raz I, Hauser E, Bursztyn M (1994) Moderate exercise improves glucose metabolism in uncontrolled elderly patients with non-insulin-dependent diabetes mellitus. Isr J Med Sci 30:766-770 
23. Ronnemaa T, Mattila K, Lehtonen A, Kallio V (1986) A controlled randomized study on the effect of long-term physical exercise on the metabolic control in type 2 diabetic patients. Acta Med Scand 220:219-224

24. Mourier A, Gautier JF, De Kerviler E et al. (1997) Mobilization of visceral adipose tissue related to the improvement in insulin sensitivity in response to physical training in NIDDM. Effects of branched-chain amino acid supplements. Diabetes Care 20:385-391

25. Moher D, Cook DJ, Eastwood S, Olkin I, Rennie R, Stroup DF (1999) Improving the quality of reports of meta-analyses of randomised controlled trials: the QUORUM statement. Lancet 354:1896-1900

26. Boulé NG, Haddad E, Kenny GP, Wells GA, Sigal RJ (2001) Effects of exercise on glycemic control and body mass in type 2 diabetes mellitus: a meta-analysis of controlled clinical trials. JAMA 286:1218-1227

27. Dickersin K, Scherer R, Lefebvre C (1994) Identifying relevant studies for systematic reviews. BMJ 309:1286-1291

28. Earle CC, Pham B, Wells GA (2000) An assessment of methods to combine published survival curves. Med Decis Making 20:104-111

29. Ainsworth BE, Haksell WL, Leon AS et al. (1993) Compendium of physical activities: classification of energy costs of human physical activities. Med Sci Sports Exerc 25:71-80

30. American College of Sports Medicine (1991) Guidelines for Exercise Testing and Prescription, 4th edn. Lea \& Febiger, Philadelphia

31. Jadad AR, Moore RA, Carroll D et al. (1996) Assessing the quality of reports of randomized clinical trials: is blinding necessary? Control Clin Trials 17:1-12

32. Schultz KF, Chalmers I, Hayes RJ, Altman DG (1995) Empirical evidence of bias: Dimensions of methodological quality associated with treatment effects in controlled trials. JAMA 273:408-412

33. The Cochrane Collaboration (2000). Appendix K. Statistical methods used in MetaView. Review Manager (RevMan) 4.1 User Guide, The Cochrane Collaboration, Oxford

34. Mulrow CD, Oxman AD (1997) Analysing and presenting results. Cochrane collaboration handbook, Sect. 8. The Cochrane Collaboration, Oxford

35. Lehmann R, Vokac A, Niedermann K, Agosti K, Spinas GA (1995) Loss of abdominal fat and improvement of the cardiovascular risk profile by regular moderate exercise training in patients with NIDDM. Diabetologia 38:1313-1319

36. Lehmann R, Engler H, Honegger R, Riesen W, Spinas GA (2001) Alterations of lipolytic enzymes and high-density lipoprotein subfractions induced by physical activity in type 2 diabetes mellitus. Eur J Clin Invest 31:37-44

37. Verity LS, Ismail AH (1989) Effects of exercise on cardiovascular disease risk in women with NIDDM. Diabetes Res Clin Pract 6:27-35

38. Maiorana A, O'Driscoll G, Cheetham C et al. (2001) The effect of combined aerobic and resistance exercise training on vascular function in type 2 diabetes. J Am Coll Cardiol 38:860-866

39. Maiorana A, O'Driscoll G, Goodman C, Taylor R, Green D (2002) Combined aerobic and resistance exercise improves glycemic control and fitness in type 2 diabetes. Diabetes Res Clin Pract 56:115-123

40. Dunstan DW, Puddey IB, Beilin LJ, Burke V, Morton AR, Stanton KG (1998) Effects of a short-term circuit weight training program on glycaemic control in NIDDM. Diabetes Res Clin Pract 40:53-61

41. Honkola A, Forsen T, Eriksson J (1997) Resistance training improves the metabolic profile in individuals with type 2 diabetes. Acta Diabetol 34:245-248
42. Bogardus C, Ravussin E, Robbins DC, Wolfe RR, Horton ES, Sims EAH (1984) Effects of physical training and diet therapy on carbohydrate metabolism in patients with glucose intolerance and non-insulin-dependent diabetes mellitus. Diabetes 33:311-318

43. Smutok MA, Reece C, Kokkinos PF et al. (1994) Effects of exercise training modality on glucose tolerance in men with abnormal glucose regulation. Int J Sports Med 15:283-289

44. Wing RR, Epstein LH, Paternostro-Bayles M, Kriska A, Nowalk MP, Gooding W (1988) Exercise in a behavioural weight control programme for obese patients with Type 2 (non-insulin-dependent) diabetes. Diabetologia 31:902-909

45. Agurs-Collins TD, Kumanyika SK, Ten Have TR, AdamsCampbell LL (1997) A randomized controlled trial of weight reduction and exercise for diabetes management in older African-American subjects. Diabetes Care 20:15031511

46. Fujii S (1992) Physical exercise therapy in diabetes mellitus - the role of clinical laboratory examinations. Rinsho Byori 40:1129-1135

47. Fujii S, Okuno Y, Okada K et al. (1982) Effects of physical training on glucose tolerance and insulin response in diabetics. Osaka City Med J 28:1-8

48. Kaplan RM, Wilson DK, Hartwell SL, Merino KL, Wallace JP (1985) Prospective evaluation of HDL cholesterol changes after diet and physical conditioning programs for patients with Type 2 diabetes mellitus. Diabetes Care 8:343-348

49. Kaplan RM, Hartwell SL, Wilson DK, Wallace JP (1987) Effects of diet and exercise interventions on control and quality of life in non-insulin-dependent diabetes mellitus. J Gen Intern Med 2:220-228

50. Blonk MC, Jacobs MA, Biesheuvel EH, Weeda-Mannak WL, Heine RJ (1994) Influences on weight loss in type 2 diabetic patients: little long-term benefit from group behaviour therapy and exercise training. Diabet Med 11:449-457

51. Samaras K, Ashwell S, Mackintosh AM, Fleury AC, Campbell LV, Chisholm DJ (1997) Will older sedentary people with non-insulin-dependent diabetes mellitus start exercising? A health promotion model. Diabetes Res Clin Pract 37:121-128

52. Skarfors ET, Wegener TA, Lithell H, Selinus I (1987) Physical training as treatment for Type 2 (non-insulin-dependent) diabetes in elderly men-a feasibility study over 2 years. Diabetologia 30:930-933

53. Dunstan DW, Mori TA, Puddey IB et al. (1999) A randomised, controlled study of the effects of aerobic exercise and dietary fish on coagulation and fibrinolytic factors in type 2 diabetics. Thrombosis and Haemostasis 81:367-372

54. Mori TA, Dunstan DW, Burke V et al. (1999) Effect of dietary fish and exercise training on urinary F2-isoprostane excretion in non-insulin-dependent diabetic patients. Metabolism 48:1402-1408

55. Ronnemaa T, Marniemi J, Puukka P, Kuusi T (1988) Effects of long-term physical exercise on serum lipids, lipoproteins and lipid metabolizing enzymes in type 2 (non-insulin-dependent) diabetic patients. Diabetes Res 7:79-84

56. Vanninen E, Uusitupa M, Lansimies E, Siitonen O, Laitinen J (1993) Effect of metabolic control on autonomic function in obese patients with newly diagnosed type 2 diabetes. Diabet Med 10:66-73

57. Uusitupa MI (1996) Early lifestyle intervention in patients with non-insulin-dependent diabetes mellitus and impaired glucose tolerance. Ann Med 28:445-449

58. Hauser E. The effects of physical activity on weight, glucose metabolism and lipid profile in uncontrolled type $2 \mathrm{di}$ abetic patients. The school of Public Health and Community Medicine. The Hebrew University, Jerusalem 
59. Boudou P, De Kerviler E, Vexiau P, Fiet J, Cathelineau G, Gautier J (2000) Effects of a single bout of exercise and exercise training on steroid levels in middle-aged type 2 diabetic men: relationship to abdominal adipose tissue distribution and metabolic status. Diabetes Metab 26:450-457

60. Boudou P, Kerviler E de, Erlich D, Vexiau P, Gautier JF (2001) Exercise training-induced triglyceride lowering negatively correlates with DHEA levels in men with type 2 diabetes. Int J Obes 25:1108-1112

61. American College of Sports Medicine (1995) Guidelines for exercise testing and exercise prescription, 5 th edn. Lea \& Febiger, Philadelphia

62. Ainsworth BE, Haskell WL, Whitt MC et al. (2000) Compendium of physical activities: an update of activity codes and MET intensities. Med Sci Sports Exerc 32:S498S504

63. Goodpaster BH, Thaete FL, Simoneau JA, Kelley DE (1997) Subcutaneous abdominal fat and thigh muscle com- position predict insulin sensitivity independently of visceral fat. Diabetes 46:1579-1585

64. Simoneau JA, Colberg SR, Thaete FL, Kelley DE (1995) Skeletal muscle glycolytic and oxidative enzyme capacities are determinants of insulin sensitivity and muscle composition in obese women. FASEB J 9:273-278

65. Roy TM, Peterson HR, Snider HL et al. (1989) Autonomic influences on cardiovascular performance in diabetic subjects. Am J Med 87:382-388

66. American College of Sports Medicine (1998) American College of Sports Medicine position stand. Exercise and physical activity for older adults. Med Sci Sports Exerc 30:992-1008

67. Whipp BJ, Davis JA, Torres F, Wasserman K (1981) A test to determine parameters of aerobic function during exercise. J Appl Physiol 50:217-221

68. Astrand PO (1977) Textbook of work physiology. McGraw-Hill, New York, pp 333-365 